

\title{
The Current Situation of Female Scientists in Argentina
}

Ana María Llois and Silvina Ponce Dawson

Citation: AIP Conference Proceedings 1119, 75 (2009); doi: 10.1063/1.3137914

View online: http://dx.doi.org/10.1063/1.3137914

View Table of Contents: http://scitation.aip.org/content/aip/proceeding/aipcp/1119?ver=pdfcov

Published by the AIP Publishing

Articles you may be interested in

A National Workshop in the United States to Prepare New Faculty in Physics and Astronomy

AIP Conf. Proc. 1263, 12 (2010); 10.1063/1.3479849

Status of Women In Physics in Australia

AIP Conf. Proc. 1119, 79 (2009); 10.1063/1.3137916

Women in Physics in Yemen

AIP Conf. Proc. 1119, 195 (2009); 10.1063/1.3137772

Vietnamese Women in Physics

AIP Conf. Proc. 1119, 193 (2009); 10.1063/1.3137771

The training, careers, and work of Ph.D. physical scientists: Not simply academic

Am. J. Phys. 70, 1081 (2002); 10.1119/1.1510884 


\title{
The Current Situation of Female Scientists in Argentina
}

\author{
Ana María Llois ${ }^{\mathrm{a}, \mathrm{b}}$ and Silvina Ponce Dawson ${ }^{\mathrm{b}}$ \\ ${ }^{a}$ Departamento de Física, TANDAR CNEA, San Martin; ${ }^{b}$ Departamento de Fisica, FCEN-UBA, \\ Ciudad Universitaria, Buenos Aires
}

\begin{abstract}
We report the changes that have taken place recently regarding the situation of female scientists in Argentina. We comment on the rules for maternity leave that have been passed recently for research scholars doing their PhDs and on the number of women scientists that occupy decision making-positions in science. We also present some evidence that seems to indicate that, among young scientists, women are more willing to occupy leadership positions and that the Argentinean society is more accepting of this new role.
\end{abstract}

Keywords: women in physics, Argentina, female leadership in physics

PACS: $01.75 .+\mathrm{m}, 01.78 .+\mathrm{p}, 01.85 .+\mathrm{f}$

Our first paper on the situation of female physicists in Argentina [1] reported that a relatively large percentage of physics students were female (around 30\%) and that a similar fraction of women occupied the lowest levels in the academic ladder. However, that fraction dropped significantly at higher level positions. We also pointed out the lack of interest that the Argentine society at large had for science-related issues. In our second paper [2] we reported the results of a survey with which we tried to explore, among other things, to what extent family matters interfered with career development in the case of female scientists. Although the sample of physicists that participated in the survey was not very large, the results corroborated our suspicion that family-related issues affected the careers of women to a larger extent than those of men. Among the 67 physicists who participated of the survey, female physicists tended to have more children than male physicists did, and most had them earlier in their careers. The time it took for the women physicists of the survey to finish their studies was longer, on average, than it was for men.

Whereas 18 of the 26 male $\mathrm{PhD}$ respondents had been postdocs at a major institution abroad, only seven of the 22 female $\mathrm{PhDs}$ had had such an experience. Having a successful experience abroad can have a large positive impact on the subsequent development of a scientific career in Argentina; it is important not only in terms of the personal $\mathrm{CV}$, but because of the network of connections that it provides. These results pointed to the relative disadvantage that women could face in hiring or promotion decisions when compared with men. Although the results of the survey were not conclusive, it seemed that the extra difficulties that family-related issues bore on women could be affecting their possibilities for advancement.

Some of the actions that the team who attended the first IUPAP Women in Physics Conference in 2002 undertook were aimed at generating awareness about this situation. In particular, a gender committee of the Argentine Physical Society (AFA) was organized as a means by which women physicists in Argentina could interact, share their problems, seek solutions, and exchange useful information. Several talks on the situation of women physicists were given at various research institutions and a session on the subject was organized at the annual encounter of the AFA, immediately after the second IUPAP Women in Physics Conference. Members of the committee participated of various activities organized to discuss the situation of female scientists in general. The subject of these discussions was depicted in several newspaper articles.

The AFA gender committee also made suggestions to AFA about the types of changes that could be introduced in order to alleviate the extra burden of combining a scientific career with raising a family. AFA embraced the suggestions and was planning to present them to the relevant national authorities. In the meantime, some changes were introduced by CONICET (the Argentine national research council, which is similar to the French CNRS) in this regard, which are very promising. CONICET awards $40 \%$ of the research scholarships that are granted each year in the country, mostly in support of graduate students earning their PhDs. Starting last year, female CONICET scholars that have babies during the term of their scholarships are allowed to take up to 100 days of paid leave and the term of the scholarship is extended for as many days as the duration of the leave. The University of Buenos Aires already had a similar rule, but the fact that CONICET has introduced such a change will have a much larger impact in the whole country.

In spite of this advancement, some other changes are still necessary. In particular, it is up to individual evaluators, still mostly men, whether to take into account a $\mathrm{PhD}$ candidate's time spent during the first years of child

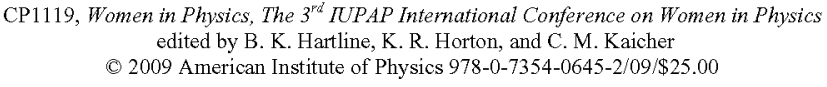


care for evaluation purposes. There is nothing formally established about it and usually it is impossible to obtain the information from reports or CVs without a personal knowledge of the individuals involved. Having chronological age limitations to access certain positions is another point that should be reformulated. We expect that the growing number of women in positions of power may translate into the introduction of new policies in this regard.

A woman has been elected president of Argentina for the first time in the history of the country. Since her inauguration, the status that is given to science issues has undergone a positive change and the number of women in science-related decision-making positions has also increased. The former Secretariat of Science, Technology and Production Innovation, which was within the Department of Education, is now a department on its own and is in charge of several secretariats. Among them, the secretariat that deals with science policies is headed by a woman (a chemist). For the first time, a woman (a physicist) has been appointed as president of CONICET, the main institution in charge of promoting science and technology in Argentina. The president of the Atomic Energy Commission is once again a woman. Argentinean society accepts these appointments and is ripe for the changes that are needed to fully include the whole universe of scientists into the scientific system.

In Argentina women studied physics from the very beginning of the creation of the career as such. However, not many women could reach the highest levels or occupy decision-making positions in the past (with the exception of the Atomic Energy Commission, which was already headed by a female physicist in the early eighties). There were no written prohibitions, but neither the general social atmosphere with its cultural prejudices, nor the attitudes of men in power positions within the scientific system were prepared to include the $35 \%$ of the physicists fully into the system. Changes are occurring at an accelerated pace since a woman was selected for the first time to become a member of the National Academy of Sciences, something that happened less than 10 years ago. The first female academician was the physicist Mariana Weissmann, who was also a winner of one of the L'Oreal-UNESCO prizes for Women in Science in 2003.

Although policies may change quickly, cultural changes usually take much longer. We have the perception that younger generations are more aware of the situation of women and that young men are more willing to accompany the decisions of their partners related to career advancement. We have noticed that nowadays it is not so unusual for married couples to relocate for the sake of the wife's scientific career. The fact that the fraction of grants recently awarded by the National Agency for the Promotion of Science and Technology (ANPCyT) to groups headed by women in the area of physics, mathematics, and astronomy is higher at the junior level than at the level of consolidated groups ( $40 \%$ and $26 \%$, respectively) may be an indication of a generational change in terms of group leadership in science. In spite of these positive signs, there still is a certain degree of "machismo" in the air, especially when it comes to judging the attitudes and decisions of women in positions of power. That will certainly take much longer to change.

\section{ACKNOWLEDGMENTS}

The participation of the Argentine team in the IUPAP Women in Physics Conference 2008 is possible thanks to the financial support of Santa Fe Institute (USA), the FCEN-UBA Physics Department (Argentina), CONICET (Argentina), and by the organizers of the Conference. We acknowledge useful comments by Dolores Carrer on the distribution of ANPCyT grants among women.

\section{REFERENCES}

1. S. Ponce Dawson and K. Hallberg, "Women in Physics in Argentina," in Women in Physics, the IUPAP International Conference, AIP Conference Proceedings 628, New York: American Institute of Physics, 2002, pp. 121-122 [http://proceedings.aip.org/proceedings/confproceed/628.jsp].

2. S. Ponce Dawson, "Women in Physics in Argentina," in Women in Physics, 2nd IUPAP International Conference, AIP Conference Proceedings 795, New York: American Institute of Physics, 2005, pp. 85-86

[http://proceedings.aip.org/proceedings/confproceed/795.jsp]. 